\title{
Unmasked Enthusiasm for Aluminum Casting
}

\section{Lynne Robinson}

Editor's Note: This is excerpted from an article that first appeared on MaterialsTechnology@TMS. Go to http://materialstechnology.tms.org/edu/article.aspx ?articleID $=2887$ to read the full article.

They keep silent watch over the long, dim corridor to the Carnegie Mellon University bookstore in Pittsburgh - dozens of faces, capturing in aluminum the often intimate thoughts of students who had walked that same hall years before. Hands figure prominently in the collage as well, thoughtfully supporting chins, clenching mouths shut or provocatively beckoning the viewer for a closer look. But it's the fanciful embellishments that truly provide insights, from chains, to foliage, to animals melding with the human image.

Every year for nearly 20 years, Ron Bennett, professor of art at Carnegie Mellon, has added a new group of sophomore students to the wall as the signature project for his Introduction to Foundry class. The birth of this tradition actually grew out of necessity, as Bennett tried to determine an effec- tive approach to teaching difficult foundry techniques.

"For the first few years that I taught the class, the students were all making different sculptures, each with a different casting problem," said Bennett. "We were spending more time on the process than the art."

The idea to level the instructional playing field with the aluminum mask project came to Bennett while he observed his advanced sculpture students making molds of each other's faces. "One student joked that 'we should put our faces on the wall so we could be remembered forever.' Then, it came to me," recalled Bennett. "As soon as the students take their faces out of the mold, and see that it's them, it becomes a very precious thing to them. They have a respect for it that they don't quite have with other work that they created."

Having all the students work on roughly the same project has also limited the casting issues they encounter, so that "the technical stuff doesn't get
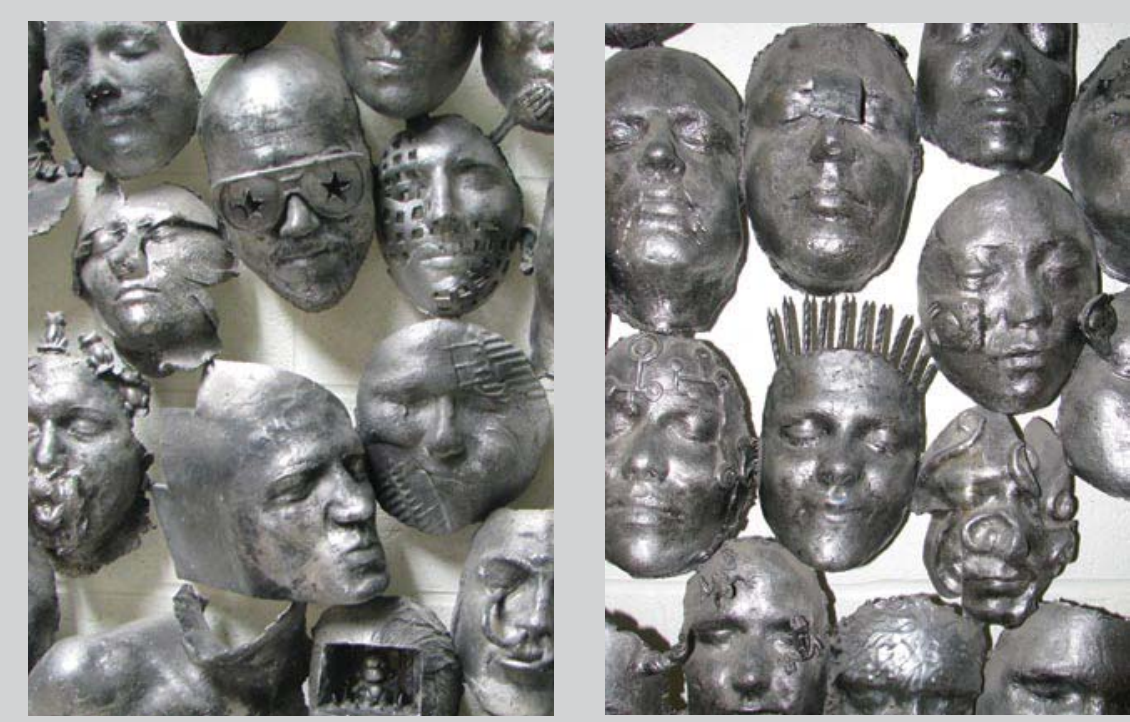

a b

Figure 1. $(a, b)$ The many faces of Professor Ron Bennett's Introduction to Foundry students. Photos by James J. Robinson. in the way of the artistic vision," said Bennett.

Bennett has his students create their masks using the lost wax process in a traditional plaster bound investment because "it is the most forgiving sculptural form." The work begins with the students' layering each other's faces with wet strips of surgical plaster to create molds. The students then prepare wax forms by painting a thin layer of melted sculpting wax on the inside of the molds. After peeling away the cooled wax to reveal exact replicas of their faces, the students carve the masks and model additional wax sculptures on top of them.

The wax sculptures are then carefully surrounded with plaster and the resulting molds are baked upside down in a kiln so the wax pours out. The finished investments are packed in sand to be filled with aluminum Alloy 319 , melted in the university's high-frequency electric furnace. The metal masks are finally revealed after the students chisel and sandblast away the investments.

"For many artists, the only reason for metal casting is to make work permanent. The real art is sculpting in wax," said Bennett. "But, there is something magical about melted metal, as well. So, other sculptors work with the idea that metal flows, that liquid turns into solid, and use that as content for their work."

Every few years, Bennett adds his own face to the wall, with each piece offering a glimpse of his interests and ideas of that time. As he nears retirement, his latest one sports a fishing hat piled high with a day's catch. He laughs as he considers the image.

"I've watched myself grow old on that wall."

Lynne Robinson is a writer for Materials Technology@TMS. 